\title{
Site-Specific Protein Modifications by an Engineered Asparaginyl Endopeptidase from Viola canadensis
}

\author{
Yu Chen ${ }^{1,2}$, Dingpeng Zhang ${ }^{1,2}$, Xiaohong Zhang ${ }^{1,2}$, Zhen Wang ${ }^{1,2}$, Chuan-Fa Liu ${ }^{1,2,3}$ and \\ James $P$. Tam ${ }^{1,2,3 *}$ \\ ${ }^{1}$ School of Biological Sciences, Nanyang Technological University, Singapore, Singapore, ${ }^{2}$ Synzymes and Natural Products \\ Center, Nanyang Technological University, Singapore, Singapore, ${ }^{3}$ Nanyang Institute of Structural Biology, Nanyang \\ Technological University, Singapore, Singapore
}

OPEN ACCESS

Edited by:

Hideo Iwaï

University of Helsinki, Finland

Reviewed by:

Thomas Durek,

The University of Queensland,

Australia

Francisco Solano,

University of Murcia, Spain

*Correspondence:

James $P$. Tam

JPTam@ntu.edu.sg

Specialty section:

This article was submitted to

Chemical Biology,

a section of the journal

Frontiers in Chemistry

Received: 01 September 2021

Accepted: 06 October 2021

Published: 22 October 2021

Citation:

Chen Y, Zhang D, Zhang X, Wang Z,

Liu C-F and Tam JP (2021) Site-

Specific Protein Modifications by an

Engineered Asparaginyl

Endopeptidase from Viola canadensis.

Front. Chem. 9:768854.

doi: 10.3389/fchem.2021.768854
Asparaginyl endopeptidases (AEPs) or legumains are Asn/Asp (Asx)-specific proteases that break peptide bonds, but also function as peptide asparaginyl ligases (PALs) that make peptide bonds. This ligase activity can be used for site-specific protein modifications in biochemical and biotechnological applications. Although AEPs are common, PALs are rare. We previously proposed ligase activity determinants (LADs) of these enzymes that could determine whether they catalyze formation or breakage of peptide bonds. LADs are key residues forming the $S 2$ and $S 1^{\prime}$ substrate-binding pockets flanking the $\mathrm{S} 1$ active site. Here, we build on the LAD hypothesis with the engineering of ligases from proteases by mutating the $S 2$ and $S 1$ ' pockets of $V_{C} A E P$, an AEP from Viola canadensis. Wild type VcAEP yields $<5 \%$ cyclic product from a linear

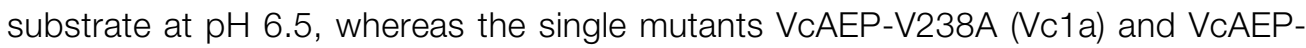
$\mathrm{Y} 168 \mathrm{~A}(\mathrm{Vc} 1 \mathrm{~b})$ targeting the $\mathrm{S} 2$ and $\mathrm{S} 1^{\prime}$ substrate-binding pockets yielded 34 and $61 \%$ cyclic products, respectively. The double mutant VcAEP-V238A/Y168A (Vc1c) targeting both the $\mathrm{S} 2$ and $\mathrm{S}^{\prime}$ ' substrate-binding pockets yielded $>90 \%$ cyclic products. Vc1c had cyclization efficiency of $917,759 \mathrm{M}^{-1} \mathrm{~s}^{-1}$, which is one of the fastest rates for ligases yet reported. Vc1c is useful for protein engineering applications, including labeling of DARPins and cell surface MCF-7, as well as producing cyclic protein sfGFP. Together, our work validates the importance of LADs for AEP ligase activity and provides valuable tools for site-specific modification of proteins and biologics.

Keywords: asparaginyl endopeptidases, peptide asparaginyl ligases, ligase-activity determinant, Viola canadensis, cell surface labeling, protein engineering

\section{INTRODUCTION}

Asparaginyl endopeptidases (AEP), also known as legumain and vacuolar processing enzymes (VPE), belong to the C13 family of cysteine proteases, which break peptide bonds after Asn/Asp (Asx) residues (Abe et al., 1993; Bottari et al., 1996; Shimada et al., 2003). AEP is initially synthesized as an inactive precursor which undergoes an acidic auto-activation in the vacuole (plants) or lysosome (mammals) (Müntz and Shutov 2002; Dall and Brandstetter 2016). AEPs are particularly well studied in plants and are multifaceted enzymes that display three distinct enzymatic functions: proteolysis, splicing, and ligation. 
AEPs were discovered as endopeptidases in the early 1990s, but were also shown to be splicing enzymes that posttranslationally modify the circularly permutated lectin concanavalin A (Min and Jones 1994; Nonis et al., 2021). Recently, certain AEPs were shown to be potent peptide Asxspecific ligases that can serve as bioprocessing enzymes for maturation of cyclic peptides (Nguyen et al., 2014; BernathLevin et al., 2015; Harris et al., 2015; Yang et al., 2017; Jackson et al., 2018; Zauner et al., 2018; Harris et al., 2019; Hemu et al., 2019; Hemu et al., 2020). As such, AEPs play important roles in processing seed storage proteins to release nutrients and bioactive peptides, forming seed coats, regulating programmed cell death, and generating host-defense antimicrobial and anti-fungal peptides (Hara-Nishimura, Inoue and Nishimura 1991; Saska et al., 2007; Hatsugai et al., 2015; Dall and Brandstetter 2016; Loo et al., 2016; Yamada et al., 2020).

Of particular interest to chemical biology is the discovery that AEPs have potent and specific ligase activity for forming Asxpeptide bonds. Our laboratory termed AEP-type ligases that can reverse the enzymatic direction from proteolysis to ligation as peptide Asn/Asp-specific ligases (PALs) (Nguyen et al., 2014; Hemu et al., 2019; Hemu et al., 2020; Tam et al., 2020). Butelase-1, the prototypic PAL, was isolated from a cyclotide-producing plant Clitoria ternatea, a plant which is known locally as bunga telang from which the name butelase is derived (Nguyen et al., 2014). Butelase-1 is highly efficient in ligating various Asx-containing peptides and proteins at $\mathrm{pH} 4-6.5$, an acidic $\mathrm{pH}$ range which generally favors proteolysis by legumains (Nguyen et al., 2015b). Consequently, butelase-1 has become a model for engineering an AEP to a PAL. In addition, butelase1like PALs are valuable tools for engineering and site-specific modification of proteins, and for theranostics. Such PALs can drive macrocyclization, orthogonal ligation, antibody-drug conjugation, and protein-protein fusion reactions (Nguyen et al., 2015a; Nguyen et al., 2015b; Cao et al., 2015; Cao et al., 2016; Hemu et al., 2016; Nguyen et al., 2016; Bi et al., 2017; Wang et al., 2021; Zhang et al., 2021).

AEPs and PALs share similar structures that include a core domain, linker region, and cap domain, with identical catalytic triads composed of Cys, His and Asn (Supplementary Figure S1). To date, 16 unique AEP and PAL structures have been reported in the protein data bank. However, their superimposed structures with $<1.2 \AA$ deviations show little difference and yield no clear clues about the enzymatic directionality toward protease or ligase activity (Supplementary Figures S2, S3, Supplementary Tables S1, S2). To understand the molecular determinants underpinning the directionality of AEP and PAL activity, our laboratory has focused on the substrate-binding sites flanking the S1 pocket. We used the Schechter and Berger's nomenclature of protease, substrate-binding pockets $(\mathrm{Sn})$ which are the sub-sites of protease beside the active site ( $\mathrm{S} 1$ pocket), to represent the region on the surface of an enzyme that can interact with peptide substrate residues $(\mathrm{Pn})$ with specificity (Supplementary Figure S4) (Abramowitz, Schechter and Berger 1967). AEPs and PALs show high amino acid sequence conservation around the catalytic $\mathrm{S} 1$ pocket and have minor differences in the S2 and S1' binding pockets. These sequence differences are termed ligase activity determinants (LADs) (Hemu et al., 2019). According to the LAD hypothesis, critical residues in the $\mathrm{S} 2$ and $\mathrm{S} 1^{\prime}$ binding pockets that flank the catalytic S1 site are essential to steer the directionality of a legumain towards hydrolase or ligase activity (Hemu et al., 2019). Modification of these critical residues by site-directed mutagenesis was shown to either affect the enzymatic efficiency or alter the enzymatic directionality of AEPs. Our team performed extensive mutagenesis on OaAEP1b, an AEP originated from Oldenlandia affinis (Yang, et al., 2017). We found that the C247A mutation displayed enhanced kinetic efficiency relative to wild type. Accordingly, we coined the term "gate-keeper", a term preceding our use of "LAD1", to describe the importance of this site in controlling ligase activity. Recently, our group discovered asecond determinant for ligase activity which we named LAD2. We showed the importance of LAD2 for controlling ligase activity of AEPs by generating several AEP mutants derived from Viola yedoensis (VyPAL3-Y175G) and Viola canadensis (VcAEP-Y168A) (Hemu et al., 2019). Also, we successfully engineered butelase-2, which displays dominant protease activity at $\mathrm{pH} 4-6.5$, to exhibit ligase activity, also at acidic $\mathrm{pH}$, by mutagenesis of key LAD residues (Hemu et al., 2020). However, additional validation to strengthen the LAD hypothesis is needed.

Here we report engineering of VcAEP, an AEP from the plant Viola canadensis, based on the LAD hypothesis to reverse its enzymatic direction from an asparaginyl endopeptidase to a ligase. VcAEP is a dual-functional AEP that displays both protease and ligase activities. Our previous work has shown that modification of LAD2 site improved ligase activity of VcAEP. In the current study, we performed mutagenesis targeting the VcAEP S2 and $\mathrm{S1}^{\prime}$ pockets individually and jointly. We show that these mutants displayed enhanced ligase activity and diminished protease activity. Furthermore, we show that a double mutated VcAEP at both LAD sites is a highly efficient ligase and useful as a tool for protein labeling, sfGFP cyclization, and cell-surface labeling.

\section{MATERIALS AND METHODS}

\section{Data-Mining Search of AEP Analogs}

The core domains of butalase-1 and OaAEP1b were used to perform a data-mining search to discover novel AEPs having ligase activity. Results of this search were further narrowed in a second search that specified Val/Ile/Cys at "gate-keeper" sequences. VcAEP has $68.2 \%$ sequence identity and $85.7 \%$ similarity with butelase-1 and $65.9 \%$ identity and $89.1 \%$ similarity with OaAEP1b. VcAEP has a Val at the "gatekeeper" position, and thus is considered to be a ligase.

\section{Expression, Purification, Activation of VcAEP}

The full sequence of VcAEP was inserted into pET28a(+) and an $\mathrm{N}$-terminal His-Ub tag was added to facilitate purification. The recombinant construct was transformed into E. coli SHuffle T7 cells, which were cultured at $30^{\circ} \mathrm{C}$ to $\mathrm{OD}_{600} 0.5$. Then, $0.1 \mathrm{mM}$ IPTG was added to induce VcAEP protein expression at $16^{\circ} \mathrm{C}$ for 
$\sim 18 \mathrm{~h}$. Cell pellets were collected and lysed in lysis buffer $(50 \mathrm{mM}$ HEPES, $300 \mathrm{mM} \mathrm{NaCl}, 1 \mathrm{mM} \mathrm{MgCl} 2,1 \mu \mathrm{l} / 25 \mathrm{ml}$ DNase I, $0.1 \%$ TritonX-100, 1mM PMSF, $\mathrm{pH}$ 7) with sonication. After centrifugation, the supernatant was collected and subjected to a three-step purification, including immobilized metal affinity chromatography, ion-exchange chromatography, and size exclusion chromatography. Activation of purified proenzyme was performed under acidic conditions $(20 \mathrm{mM}$ phosphate buffer, $0.5 \mathrm{mM} \mathrm{N}$-Lauroylsarcosine, $\mathrm{pH} 4.5$ ) at $37^{\circ} \mathrm{C}$ for $15-30 \mathrm{~min}$. In addition, the activation was conducted by adding $1 \%$ or $5 \%$ acetic acid to adjust the $\mathrm{pH}$ to $4-4.5$ with $0.5 \mathrm{mM} \mathrm{N}$-Lauroylsarcosine, at $4^{\circ} \mathrm{C}$ for $10-16 \mathrm{~h}$. The active form of the enzyme was purified by size exclusion chromatography using acidic buffer (20 mM HEPES, $150 \mathrm{mM} \mathrm{NaCl}, 1 \mathrm{mM}$ EDTA, $1 \mathrm{mM}$ DTT, 5\% glycerol, pH 4). The purified active form of the enzyme was stored at $-80^{\circ} \mathrm{C}$. Ingel digestion followed by MS/MS de novo sequencing was performed to characterize autocleavage sites in the $\mathrm{C}$ terminus.

\section{pH-Dependent Cyclization}

To determine the optimal $\mathrm{pH}$ for cyclization activity of VcAEP and mutants, reaction mixtures containing the active enzyme (200 $\mathrm{nM}$ for wild type and $100 \mathrm{nM}$ for Vcla-1c) and substrate ( $4 \mu \mathrm{M}$ for wild type, $20 \mu \mathrm{M}$ for $\mathrm{Vcla}, 50 \mu \mathrm{M}$ for $\mathrm{Vclb}$, and $100 \mu \mathrm{M}$ for $\mathrm{Vclc}$ ) were incubated at $37^{\circ} \mathrm{C}$ for $15 \mathrm{~min}$ according to the catalytic efficiency. The reaction buffers contain $20 \mathrm{mM}$ phosphate, $1 \mathrm{mM}$ EDTA, $1 \mathrm{mM}$ DTT. The wild-type VcAEP displays slow enzymatic activity compared to the mutants, and no product was observed in 15 min using the same enzyme:substrate ratio as the mutants. Thus, for the wild type VcAEP, we increased the enzyme concentration from 100 to $200 \mathrm{nM}$. Similarly, we decreased the substrate concentration to $4 \mu \mathrm{M}$. Reaction products were analyzed by calculating the peak areas of MALDI-TOF mass spectrometry.

\section{Kinetics Study Using FRET-Mediated Assay}

A kinetics study of enzyme cyclization and ligation was conducted using fluorescence resonance energy transfer (FRET) at $37^{\circ} \mathrm{C}$ and $\mathrm{pH}$ 6.5. Fluorescence was recorded with a BioTek Cytation 5 cell imaging multimode plate reader at excitation and emission wavelengths of 390 and $460 \mathrm{~nm}$, respectively. The initial rates $\mathrm{V}_{0}(\mu \mathrm{M} / \mathrm{s})$ for different substrate concentrations were calculated using the Michaelis-Menten equation. Vmax and $\mathrm{Km}$ and consequently kcat and $\mathrm{kcat} / \mathrm{Km}$ were calculated using GraphPad Prism. All FRET substrates were synthesized by standard Fmoc-based solid-phase peptide synthesis on rink amide resin (Alsina et al., 2000). EDANS was introduced by using Fmoc-Glu(EDANS)-OH. DABCYL was directly coupled to $\varepsilon$-amine of Lys residue in dry DCM containing $2 \mathrm{x}$ DIEA of DABSYL for $2 \mathrm{~h}$, at room temperature. All peptides were cleaved in 95\% TFA/2.5\% $\mathrm{H}_{2} \mathrm{O} / 2.5 \%$ TIS cleavage solution and purified by preparative RP-HPLC.

\section{Applications}

The synthetic fluorescent peptide EDANS-ANGI contains a signal "NGI" that can be recognized by ligases. DARPin9_26 was recombinantly expressed with an N-terminal His tag and TEV cleavage site. TEV cleavage exposes an $\mathrm{N}$-terminal dipeptide
"GL" that can function as an incoming nucleophilic attack group. The reaction was conducted at $37^{\circ} \mathrm{C}$ and $\mathrm{pH} 6.5$ with $20 \mathrm{nM} \mathrm{Vclc}$ and $4 \mu \mathrm{M}$ DARPin9_26. DARPins that are successfully ligated with fluorescent peptide produce a green color under UV radiation.

SfGFP is used as an example of Vclc-mediated protein circularization. Acyclic sfGFP was recombinantly expressed with additional PAL-recognizing tags (N-terminal Met-Ile and C-terminal Asn-Ser-Leu-His 6 ). The reaction was conducted at $37^{\circ} \mathrm{C}, \mathrm{pH} 6.5$, in the presence of $25 \mu \mathrm{M}$ GFP and $0.5 \mu \mathrm{M} \mathrm{Vc1c}$. The products were determined by high-resolution ESI-MS.

Application of Vclc for MCF-7 cell surface labeling was performed as follows. First, MCF-7 cells cultured in plates were detached and resuspended in phosphate buffer (PBS, $\mathrm{pH}$ 7.4). Then, $50 \mu \mathrm{M}$ of fluorescein-peptide and $200 \mathrm{nM}$ of ligase were added to the solution and incubated at $37^{\circ} \mathrm{C}$ for $1 \mathrm{~h}$. The cells were then washed 5 times with PBS to remove residual peptides and were resuspended in PBS buffer. FITC channels were used to detect fluorescein peptide-labeled cells.

\section{RESULTS AND DISCUSSION}

\section{Expression, Purification, and Activation of VCAEP}

The VcAEP sequence was obtained by data mining using the core domains of butelase- 1 and OaAEP1b. VcAEP has $68.2 \%$ sequence identity and $85.7 \%$ similarity with butelase- 1 and $65.9 \%$ identity and $89.1 \%$ similarity with OaAEP1b. To purify recombinant VcAEP, the cDNA sequence containing a His-Ub (hexahistidine-ubiquitin) tag was synthesized and cloned into pET28a $(+)$ (Figure 1A). The plasmid was expressed in SHuffle T7, an E. coli strain with enhanced folding capacity. The affinitypurified proenzyme of VcAEP was obtained using immobilized metal affinity chromatography (IMAC) followed by ion exchange (IEX) and size exclusion chromatography (SEC).

Similar to the previously reported OaAEP1b (Yang et al., 2017), the VcAEP proenzyme was obtained in two forms with or without a His-Ub tag (proform 1 and 2) (Figures 1A,B left, and Supplementary Figure S5). Both forms were around $50 \mathrm{kDa}$ on SDS-PAGE (Figure 1B, left upper), but only the proform $\mathbf{1}$ with a His-Ub tag was detected on western blot using an anti-His antibody (Figure 1B, left lower). The active form of VcAEP (activated form, 3) was generated by incubation at $37^{\circ} \mathrm{C}$ for $30 \mathrm{~min}$ with $0.5 \mathrm{mM}$ lauroylsarcosine to promote acidic activation at $\mathrm{pH} 4.5(20 \mathrm{mM}$ sodium phosphate buffer, $1 \mathrm{mM}$ EDTA), followed by purification by SEC using $\mathrm{pH} 4$ buffer (Figure 1B, middle and right). Autoactivation sites were determined by LC-MS/MS sequencing of the tryptic-digested active forms. The Asn/Asp cleavage sites at both ends of the core domain were N35 in the N-terminal region (NTR) and D343/D349/N360 in the cap domain (Figure 1A and Supplementary Figure S6). The cleavage sites of the truncated form and cap domain were also determined (Supplementary Figures S7, S8). The result implies that a multi-step cleavage is involved in the VcAEP acidic auto-activation. In addition, the processed activated form 3 of VcAEP retains a short cap domain, which might be helpful for the stabilization of activated form. 

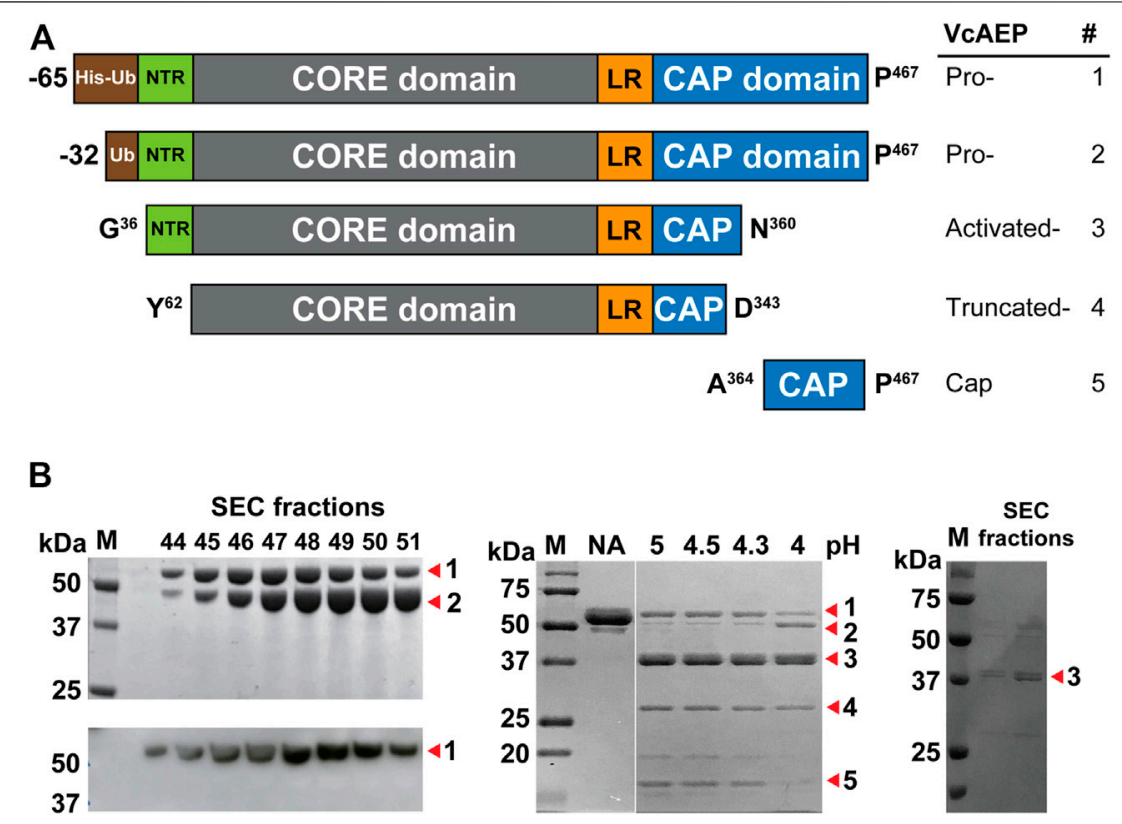

FIGURE 1 | Purification and activation of VCAEP. (A) Schematic representation of recombinant VcAEP constructs. Pro-VcAEP 1: full-length proenzyme form expressed with His-Ub-VcAEP (His = His6 tag, Ub = ubiquitin) and ending at P467. Pro-VcAEP 2: full-length VcAEP without the His-tag. Activated-VcAEP 3: active form of VcAEP after acidic autoactivation that begins with G36 and ends with N360. Truncated-VcAEP 4: truncated form of VcAEP, starting with Y62 and ending with D343. Cap 5: cleaved cap domain after acidic autoactivation, starting with A364 and ending with P467. The processing sites were determined by in-gel trypsin digestion followed by MS/MS de novo sequencing. NTR, N-terminal region; LR, linker region. (B) Purification, expression and activation of VcAEP. Left panel: analysis of purified fractions obtained from SEC chromatography, SDS-PAGE (upper) and western blot (lower). SDS-PAGE shows two bands, Pro-VcAEP 1 and Pro-VcAEP 2 (see panel A), with the lower band 2 being the VcAEP proenzyme without the His tag. Middle panel: SDS-PAGE analysis of the lauroylsarcosine-mediated acidic autoactivation of PreVCAEP 1 and Pro-VCAEP 2 and its products Activated-VCAEP 3, Truncated-VcAEP 4, and Cap 5, performed at $\mathrm{pH} 4-5$ at $37^{\circ} \mathrm{C}$ for 30 min to generate Activated-VcAEP $3(\sim 37 \mathrm{kDa})$. NA: no activation. Right panel: SDS-PAGE analysis of purified Activated-VcAEP 3 by SEC chromatography using pH 4 buffer.

\section{Characterization of VcAEP Activity}

AEPs require a tripeptide recognition motif Asx-Xaa-Yaa (P1$\mathrm{P} 1^{\prime}-\mathrm{P} 2^{\prime}$, using Schechter and Berger nomenclature) to make peptide bonds (Abramowitz et al., 1967). Generally, at the P1' position, the substrate requirements are not stringent, although small amino acid residues are typically present. At P2', bulky and aromatic amino acid residues are required for AEPs to carry out ligations (Figure 2A) (Nguyen et al., 2014; Jackson et al., 2020). We synthesized a 16-residue model peptide substrates $\mathrm{GN}^{14}$-GI (GISTKSIPPISYAN ${ }^{14}$-GI) to characterize the activity of VcAEP. The functional activity of VcAEP at pH 6 was initially assayed by MALDI-TOF mass spectrometry using $\mathrm{GN}^{14}$-GI (MW $1618 \mathrm{Da}$ ) to determine its ligation efficiency to yield the 14-residue cyclic product $\mathrm{cGN}^{14}$ (MW $1429 \mathrm{Da}$ ) or its proteolytic activity to yield the linear product $\mathrm{GN}^{14}$ (MW $1447 \mathrm{Da}$ ) (Figure 2B). Under given conditions, both cyclic (15\%) and linear products (5\%) were generated, indicating that VcAEP is a dual-function enzyme that has both protease and ligase activities (Figure 2C).

The ligase activity of AEPs and PALs is highly dependent on $\mathrm{pH}$ (Hemu et al., 2019; Hemu et al., 2020). Thus, we performed the pHdependent cyclization of VcAEP over the range of $\mathrm{pH} 4-8$ using $\mathrm{GN}^{14}$-GI. The reactions were conducted at $37^{\circ} \mathrm{C}$ for $15 \mathrm{~min}$ at the indicated $\mathrm{pH}$. The yield of cyclic product (MW $1430 \mathrm{Da}$ ) and linear product (MW $1448 \mathrm{Da}$ ) were quantified in triplicate by calculating the peak areas of MALDI-TOF mass spectrometry. VcAEP displays a low ligase activity between $\mathrm{pH}$ 4-7 toward the peptide substrate $\mathrm{GN}^{14}$-GI with a high enzyme concentration of 1:20 molar ratio of enzyme to substrate (Figure 2D).

\section{Mutants Targeting S2 and S1' Substrate-Binding Pockets Display Potent Ligase Activities}

Sequence alignment of known AEPs and ligases shows that the S1 and S3 pockets are highly conserved. Meanwhile, the S2' pocket contains four residues that have diverse sequences and are located relatively far from the catalytic $\mathrm{S} 1$ pocket (Figures 3A,B). Sequence variations of $\mathrm{S} 2$ and $\mathrm{S}^{\prime}$ substrate-binding pockets are vital factors to control the ligase activity of AEPs. The S2 pocket, also known as the "gate-keeper" or LAD1, comprises three residues, of which the first residue is an aromatic Trp or Tyr and the third residue is hydrophobic residues Ala/Val or neutral residues Thr/Tyr. The ligases tend to have $\mathrm{Val} / \mathrm{Ile} / \mathrm{Cys}$ as the middle residue, whereas proteases often have Gly. The $\mathrm{S1}^{\prime}$ pocket, also known as LAD2, has two residues. Ligases often have Gly-Ala or AlaAla or Ala-Pro, and AEPs typically have Gly-Pro. It should be noted that the ligase activity of AEP is not solely determined by substrate-binding pockets, but rather results from cooperation of different factors (Haywood et al., 2018; Jackson et al., 2018). 


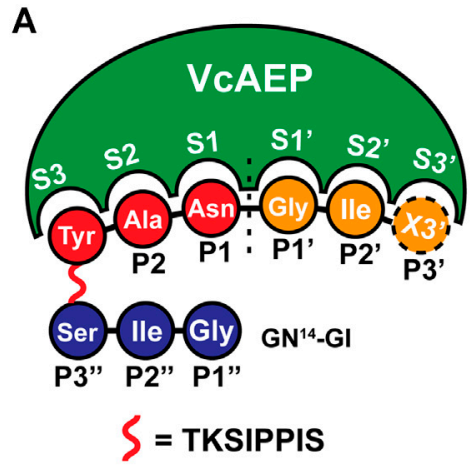

C

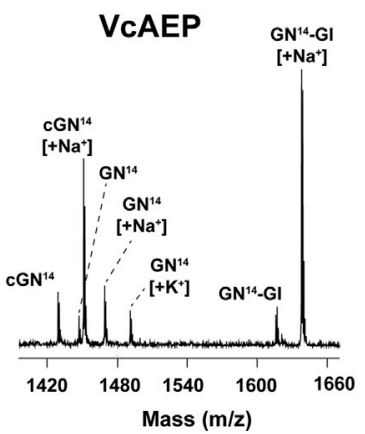

B

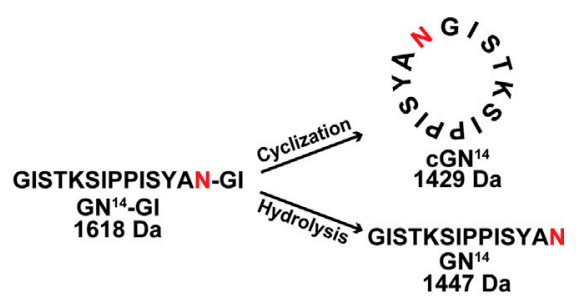

D

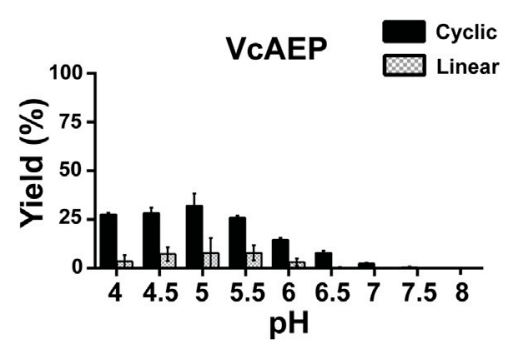

FIGURE 2 | Analysis of VCAEP AEP activity. (A) Nomenclature of AEP/PAL and substrate, using the peptide substrate GN ${ }^{14}$-GI (GISTKSIPPISYAN-GI) as a model. Based on the nomenclature of substrate binding of protease proposed by Schechter and Berger, the cleavage site of the substrate is named P1 (red), and the corresponding binding pocket of the enzyme is S1. After cleavage, the amino acid residues of leaving group are P1', P2', P3' Etc (orange). For PALs to cyclize or ligate substrate, the amino acid residues of the incoming group are P1", P2", P3" etc., (blue). X stands for the 20 amino acids. (B) Schematic representations of AEPmediated cyclization and hydrolysis of the 16-residue peptide substrate $\mathrm{GN}{ }^{14} \mathrm{~N}-\mathrm{Gl}$ (MW $\left.1618 \mathrm{Da}\right)$. The P1-Asn position is colored red. The enzymatic reaction of VcAEP yields two products: the 14-residue cyclic product cGN ${ }^{14}(1429 \mathrm{Da})$ and 14-residue linear product $\mathrm{GN}^{14}(1447 \mathrm{Da})$ with release of a Gl dipeptide. (C) Representative MALDI-TOF mass spectrometry of the cyclic product CGN ${ }^{14}$ and the linear product $G N^{14}$ generated by VcAEP together with $G N^{14} \mathrm{~N}$-Gl as the starting material. The reaction was conducted at $\mathrm{pH} 6$, at $37^{\circ} \mathrm{C}$ for 15 min with a 1:20 molar ratio of enzyme:substrate. (D) Product yields of $\mathrm{V}$ cAEP wild type were quantified by calculating the peak areas of MALDI-TOF mass spectrometry. Gray and black bars indicate the percentage yield of linear product and cyclic product, respectively. The reactions were conducted at $37^{\circ} \mathrm{C}$ for $15 \mathrm{~min}$ with a molar enzyme:substrate ratio of 1:20 (VCAEP). Average yield and SDs were calculated from experiments performed in triplicate.

Previously, our laboratory engineered eight PAL-like mutants of butelase- 2 which is an AEP with protease activity at acidic $\mathrm{pH}$. These PAL-like mutants targets both the LAD1 and LAD2 sites (see Figure 3B). They include Bu2a (V/GP), Bu2b (I/GP), and $\mathrm{Bu} 2 \mathrm{c}(\mathrm{A} / \mathrm{GP})$, targeting the middle residue of LAD1 motif Gly252 by substituting it with $\mathrm{Val}$, Ile, or Ala, respectively. We also prepared LAD2 mutants targeting Gly182-Pro183 by substituting them with Ala, giving Bu2d (G/GA) (butelase-1-like) and Bu2e (G/ AP) (VyPAL2-like). In addition, we engineered double-site-LAD mutants: Bu2f (V/AP) (VyPAL2-like), Bu2g (V/GA which is butelase-1-like), and Bu2h (V/AA whichOaAEP1b-like). The best engineered butelase- 2 mutant acting as a butelase- 1 was Bu2 $g$ which contains mutations in both LAD1 and LAD2 sites (Hemu et al., 2020).

To confirm our mutation study of converting butelase-2 from a protease to a ligase, we herein focus on engineering the S2 and $\mathrm{S1}^{\prime}$ pockets of VcAEP corresponding to the LAD1 and LAD2 sites, respectively, to promote its ligase activity and demonstrate the essential roles these factors play in AEP ligase activity. According to the LAD hypothesis, VcAEP is a bifunctional AEP with a Trp-Val-Ala sequence in the S2 pocket and thus is considered a ligase. In contrast, the $\mathrm{S1}^{\prime}$ pocket sequence of VcAEP is Tyr-Pro, which does not fit the criteria for ligases. To validate the LAD hypothesis, we engineered three mutants: VcAEP-V238A or Vcla that has an Ala substituted for Val in the middle residue in the LAD1 motif at position 238 (V238A); VcAEP-Y168A or Vc1b that has the LAD2 residue Y168 changed to Ala; and VcAEP-V238A/Y168A or Vc1c, a double mutant targeting both LAD1 and LAD2 pockets (Figure 3B). We used a similar protocol to express, purify, and activate these mutants as was used for wild type VcAEP (Supplementary Figure S9). Although Vcla and Vclb differ by a single amino acid, they migrated differently in SDS-PAGE as bands MW <37 and $>37 \mathrm{kDa}$, respectively. We do not have an explanation for this result. However, we found that Vclc and Vcla which differ also by a single amino acid migrated similarly in the SDS-PAGE.

To compare the ligase activity of the mutants Vcla-1c to the wild type VcAEP, we performed the $\mathrm{pH}$-dependent cyclization reactions mediated by Vcla-1c. The ligation reactions were performed over the $\mathrm{pH}$ range of $\mathrm{pH} 4$ to $\mathrm{pH} 8$ using the peptide substrate $\mathrm{GN}^{14}-\mathrm{GI}$, at $37^{\circ} \mathrm{C}$ for $15 \mathrm{~min}$. The yield of 


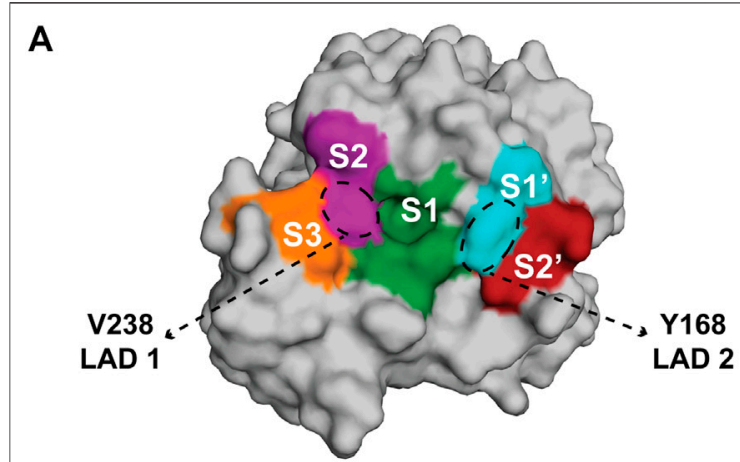

B

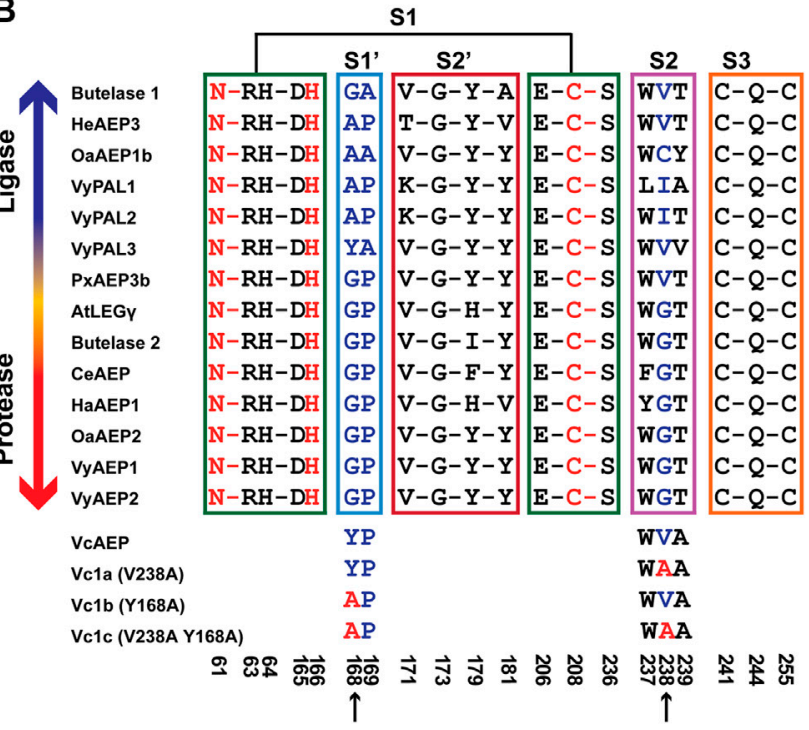

FIGURE 3 | Engineering a ligase from a dual-functional AEP, VCAEP. (A) Proposed substrate binding pockets (S3, S2, S1, S1', S2') based on the crystal structure of the VcAEP proform (pdb: 5ZBI). The S3 pocket (orange) comprises residues C241, Q244, and C255, S2 (purple) W237, V238, and A239, S1 (green) N61, R63, H64, D165, H166, E206, C208, and S236, S1' (cyan) Y168 and P169, S2' (red) V171, G173, Y179, and Y181. (B) Sequence alignment of substrate-binding pockets of known AEPs for which protease activity dominates (e.g., CeAEP, butelase-2), and PALs having dominant ligase activity (e.g., butelase-1, VyPAL2). The blue arrow indicates increasing ligase activity and the red arrow indicates increasing protease activity. The three engineered VcAEP mutants having mutations at S2 (V238 using $V_{c} A E P$ numbering) and $S_{1}^{\prime}$ (Y168) sites are $V_{c} 1 a$ (V238A), $V_{c} 1 b$ (Y168A), and Vc1c (V238A Y168A). Color codes are the same as for (A) and (B) with S3 in orange, S2 in purple, S1 in green, S1' in cyan, and S2 in red. The catalytic triad N61, H166, and C208 in the oxyanion hole corresponding to S1 is colored red. Key residues in the $\mathrm{S} 1^{\prime}$ and $\mathrm{S} 2$ pockets for steering AEP or PAL activities (panel B) are respectively colored cyan for Y168P169, and purple for V238. Residues comprising the catalytic $\mathrm{S} 1, \mathrm{~S}^{\prime}, \mathrm{S} 2{ }^{\prime}, \mathrm{S} 2$ and $\mathrm{S} 3$ pockets are framed by a green, cyan, red, purple and orange box, respectively. Three VcAEP mutants with increasing ligase activity were engineered that target S2 and $\mathrm{S} 1^{\prime}$ pockets (indicated by black arrows).

cyclic product (MW $1430 \mathrm{Da}$ ) and linear product (MW $1448 \mathrm{Da}$ ) were quantified in triplicate by MALDI-TOF mass spectrometry.

Vcla (VcAEP-V238A), a LAD1 mutant that has a V238A mutation in the $\mathrm{S} 2$ binding pocket, displayed dominant protease activity at $\mathrm{pH}<6$, but dominant ligase activity at $\mathrm{pH}>6.5$ using the $\mathrm{GN}^{14}$-GI peptide substrate at a 1:200 molar ratio of enzyme to substrate. Using the same reaction time and temperature, Vcla consumed substrate at a much faster rate than wild type VcAEP. As such, we used a 1:200 enzyme:substrate molar ratio for Vcla and 1:20 for VcAEP because Vcla is a "faster" enzyme compared to VcAEP (Figure 4A).

The process for AEP and PAL to produce linear or cyclic products mainly involves two steps: formation of an S-acyl intermediate that then undergoes nucleophilic attack by a water molecule (hydrolysis) or a free amine of the peptide substrate (ligation). LAD1 is proposed to affect the formation of the S-acyl intermediate, which is the rate-limiting step, by shifting the molecular surface toward the incoming peptide substrate to affect the overall reaction rate (Hemu et al., 2020). Therefore, substitution of Ala for Val at position 238 of LAD1 is likely to accelerate the formation of the S-acyl intermediate and the overall catalysis process, including the production of linear and cyclic products.

Vc1b (VcAEP-Y168A) has a Tyr to Ala mutation in the LAD2 pocket (Y168A) and exhibited dominant ligase activity at $\mathrm{pH}>$ 4.5 and no visible hydrolytic product at $\mathrm{pH}>6.5$ using the peptide substrate $\mathrm{GN}^{14}$-GI at a 1:500 molar ratio of enzyme to substrate. At $\mathrm{pH} 6.5$, about $60 \%$ cyclization yield was observed (Figure 4B). This result supports the LAD hypothesis that LAD2 plays a more direct role in determining AEP enzyme directionality. The wild type VcAEP has a Tyr-Pro dipeptide in LAD2, and the bulky Tyr would likely accelerate the departure of the leaving group, such that water molecules would have increased opportunity to attack the S-acyl intermediate and in turn generate more hydrolysis product. However, Vclb with an Ala-Pro dipeptide in LAD2 would retain the leaving group for a longer time to allow selectively an incoming amine group to be ligated.

The double mutant Vc1c (VcAEP-V238A/Y168A) with mutations in both LAD1 and LAD2 showed the fastest activity of all four enzymes tested. Moreover, $\mathrm{Vclc}$ generated $>80 \%$ cyclic product between $\mathrm{pH} 5$ and 6.5 using the peptide substrate $\mathrm{GN}^{14}$-GI at a 1:1000 molar ratio of enzyme:substrate (Figure 4C). Engineering both LAD1 and LAD2 in $\mathrm{Vclc}$ integrated the advantages of substitutions at both sites to enhance catalytic efficiency of peptide bond formation. Together, our results show that both LAD mutants, Vclb and $\mathrm{Vclc}$, display significant ligase activity at physiological $\mathrm{pH}$ and could be valuable for peptide/protein engineering applications.

\section{Kinetic Studies of VcAEP and Vc1a-1c}

To figure out the catalytic potency of the VcAEP and its mutants, we determined their catalytic efficiency using the fluorescence resonance energy transfer (FRET)-base assay. FRET substrates were synthesized by standard Fmoc-based solid-phase peptide synthesis on rink amide resin (Alsina et al., 2000). The fluorophore EDANS was introduced by using FmocGlu(EDANS)-OH. DABCYL was directly coupled to the $\varepsilon$-amine of Lys residue.

We initially performed the kinetics study for the wild type VcAEP and its mutant Vcla using a 17-residue peptide substrate 

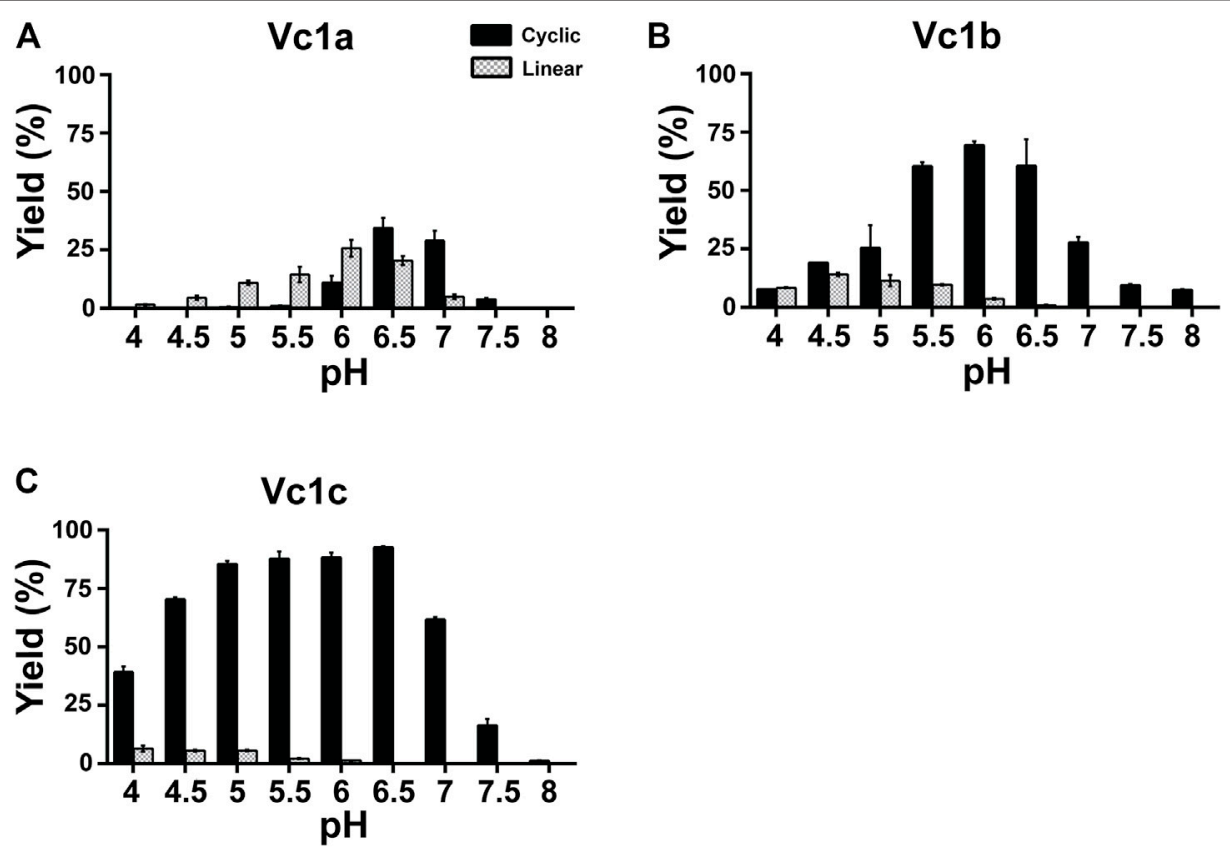

FIGURE 4 | pH-dependent cyclization efficiency of VcAEP and mutants. (A-C) Quantitative summary of VcAEP mutant Vc1a-Vc1c product yield analyzed using MALDI-TOF mass spectrometry. Gray and black bars indicate the percentage yield of linear product and cyclic product, respectively. The reactions were conducted at $37^{\circ} \mathrm{C}$ for $15 \mathrm{~min}$ with a molar enzyme:substrate ratio of 1:200 (Vc1a), 1:500 (Vc1b), and 1:1000 (Vc1c). Average yield and SDs were calculated from experiments performed in triplicate.

TABLE 1 | Kinetic parameters of VcAEP and Vc1a-1c.

\begin{tabular}{|c|c|c|c|c|c|c|}
\hline & Enzyme & kcat $\left(s^{-1}\right)$ & $\mathrm{Km}(\mu \mathrm{M})$ & kcat/Km $\left(\mathbf{s}^{-1} \mathbf{M}^{-1}\right)$ & Substrate sequence & $\begin{array}{l}\text { Enzyme concentration } \\
(\mu \mathrm{M})\end{array}$ \\
\hline \multirow[t]{4}{*}{ Cyclization } & VcAEP & 0.01863 & 4.173 & 4,464 & GISTKSIPPIE(EDANS)YRN-SLK(DABCYL) & 0.438 \\
\hline & Vc1a & 0.2025 & 13.77 & 14,700 & GISTKSIPPIE(EDANS)YRN-SLK(DABCYL) & 1.39 \\
\hline & Vc1b & 0.03471 & 1.719 & 200,192 & GISKPE(EDANS)SYAN-GIK(DABCYL) & 0.06 \\
\hline & Vc1c & 2.31 & 2.517 & 917,759 & GISKPE(EDANS)SYAN-GIK(DABCYL) & 0.044 \\
\hline Ligation & Vc1c & 0.3761 & 33.68 & 11,166 & $\begin{array}{l}\text { N-terminal: RE(EDANS)AN-Gl } \\
\text { C-terminal: GVK(DABCYL) }\end{array}$ & 0.044 \\
\hline
\end{tabular}

GISTKSIPPIE(EDANS)YRN-SLK(DABCYL). The determined $\mathrm{kcat} / \mathrm{Km}$ of VcAEP and Vcla using substrate were $4,464 \mathrm{M}^{-1} \mathrm{~s}^{-1}$ and $14,706 \mathrm{M}^{-1} \mathrm{~s}^{-1}$, respectively (Table 1). The kcat of Vcla $\left(0.2025 \mathrm{~s}^{-1}\right)$ was about 11-fold higher than that for $\operatorname{VcAEP}\left(0.01863 \mathrm{~s}^{-1}\right)$, indicating that $\mathrm{Vcla}$ can consume substrate at a much faster rate than VcAEP. Vcla also shows a 3-fold increase in kcat relative to VcAEP, suggesting that altering the S2 pocket influences substrate binding such that Vcla needs more substrate than VcAEP to perform its activity.

The peptide substrate GISTKSIPPIE(EDANS)YRNSLK(DABCYL) was difficult to purify. Consequently, we synthesized a 13-residue peptide substrate GISKPE(EDANS) SYAN-GIK(DABCYL) to study the kinetics of Vclb and Vclc. It should be pointed out that both substrates give highly favored cyclic peptides of 14 and 10 membered rings. Compared with the turnover rate (kcat) in intra-molecular ligation for wild type VcAEP $\left(0.01863 \mathrm{~s}^{-1}\right)$, the kcat for $\mathrm{Vclb}$ and Vc1c was found to increase by $2-\left(0.03471 \mathrm{~s}^{-1}\right)$ and 120 fold $\left(2.31 \mathrm{~s}^{-1}\right)$, respectively. Together with the affinity constant $\mathrm{Km}$, the catalytic efficiency $(\mathrm{kcat} / \mathrm{Km})$ of $\mathrm{Vclb}$ and $\mathrm{Vclc}$ in intra-molecular ligation was calculated to be $20,192 \mathrm{M}^{-1} \mathrm{~s}^{-1}$ and $917,759 \mathrm{M}^{-1} \mathrm{~s}^{-1}$, respectively (Table 1 ). In this regard, Vc1c shows a comparable cyclization activity to that of butelase-1 (GISTKSIPPYRN-SLAN) (Hemu et al., 2019). As such, $\mathrm{Vclc}$ is one of the most efficient peptide ligases reported thus far.

Site-specific modifications of proteins are generally intermolecular ligation reactions. To determine the capability of $\mathrm{Vclc}$ in inter-molecular reactions, we synthesized an N-terminal peptide REAN-GI with the fluorophore (EDANS) group and a C-terminal peptide GVKR with the quencher (DABCYL) group. Calculation of Michaelis-Menten kinetics for $\mathrm{Vclc}$ ligation based on FRET assay results showed a kcat/ $\mathrm{Km}$ of $11,166 \mathrm{M}^{-1} \mathrm{~s}^{-1}$ (Table 1) suggesting that the 


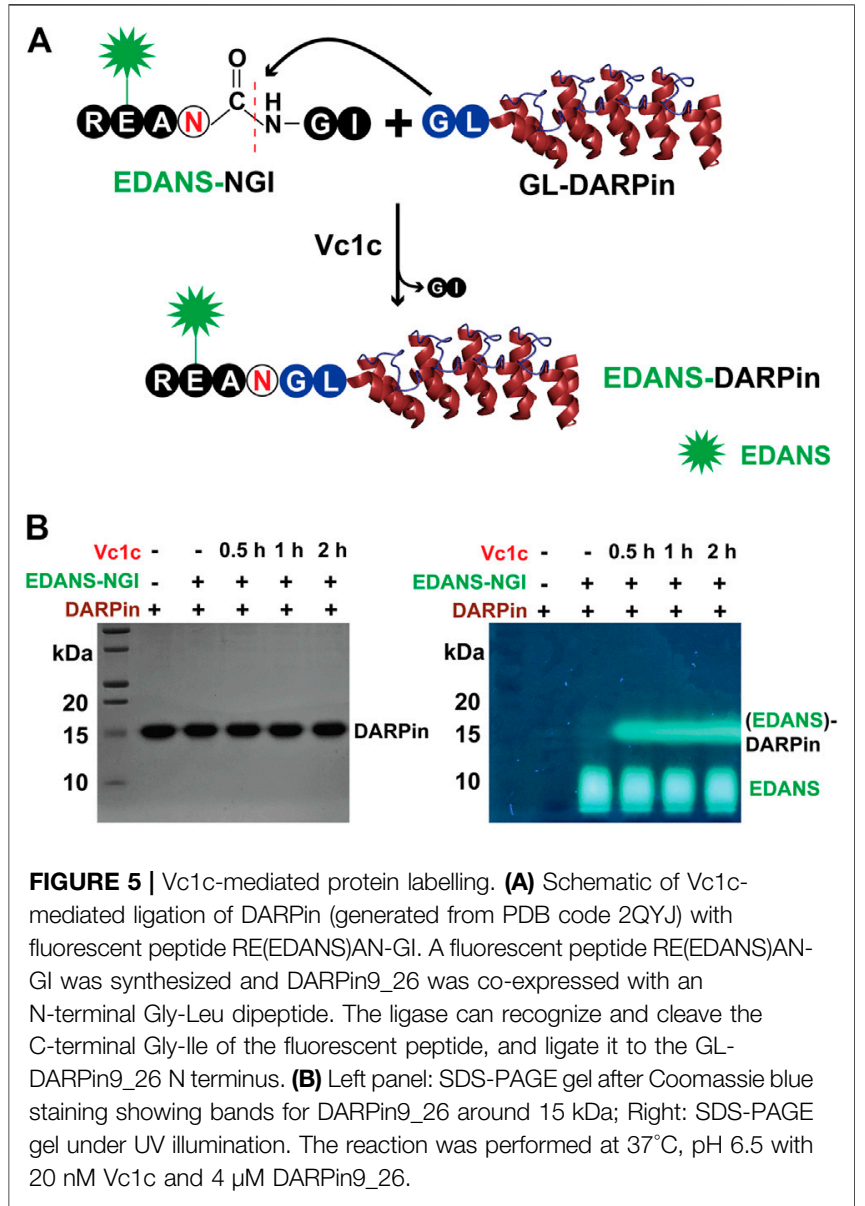

intermolecular ligation is many fold slower than intramolecular ligation which has substantially higher effective molarity than intermolecular reactions. .

\section{Application of Vc1c in Site-Specific Protein Modifications}

The catalytic parameters showed that Vclc displayed a substantially improved catalytic efficiency compared to wild type VcAEP. Next, we showed the versatility of the engineered $\mathrm{Vclc}$ as a useful tool for chemical biology, site-specific protein modification, and cell-surface labeling.

\section{Vc1c-Mediated N-Terminal Labeling of DARPin}

We first tested the activity of Vc1c in the labeling of DARPins, a genetically engineering antibody-mimetic protein based on ankyrin repeat proteins (Bork 1993). DARPins conjugated with different molecules have been used for various applications (Stumpp, Binz and Amstutz 2008). DARPin can be selected from a library to bind to any desired target, such as human epidermal growth factor receptor 2 (HER2), a transmembrane protein overexpressed on the surface of some breast cancer cells (Ross 2009). DARPins represent a new generation of protein therapeutics, and the development of various methods for DARPin labeling is of great importance.

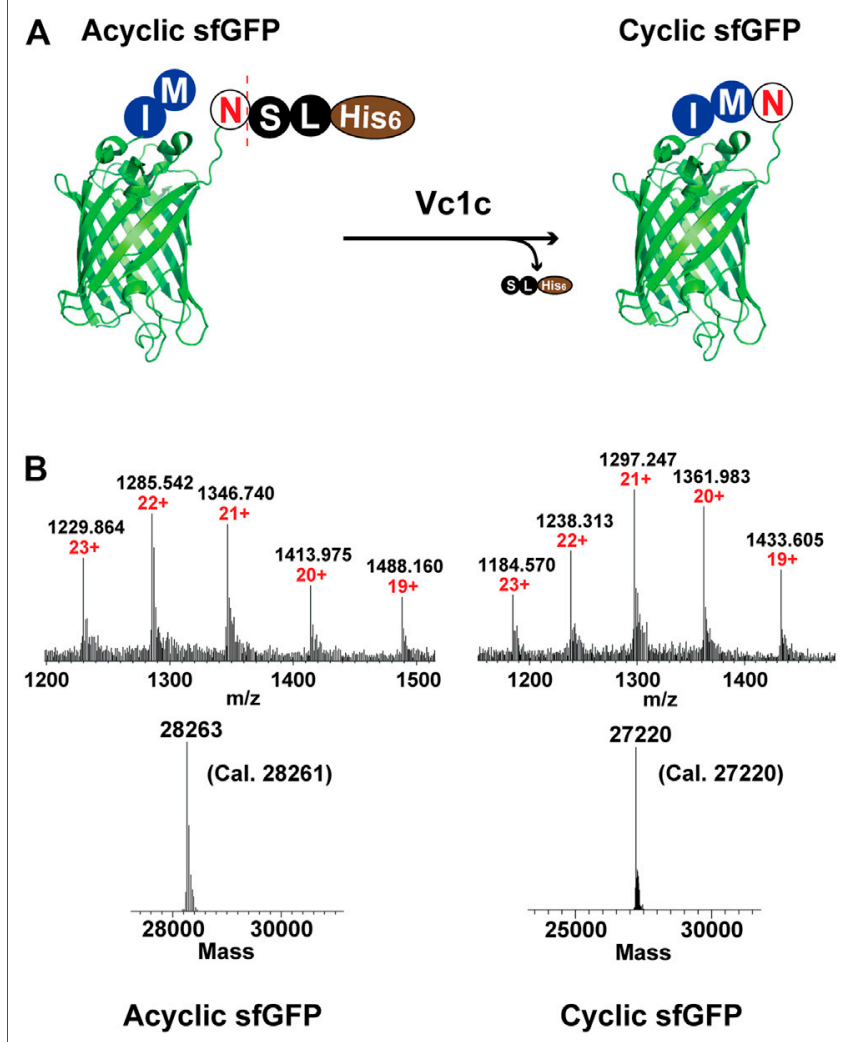

FIGURE 6 | Application of Vc1c in end-to-end cyclization of sfGFP. (A) Scheme of ligase-mediated sfGFP (generated from PDB code 2B3P) cyclization. sfGFP was co-expressed with an N-terminal Met-lle and a C-terminal Asn-Ser-Leu-His6. The ligase can recognize and cleave the C-terminal motif Ser-Leu-His6 and perform end-to-end cyclization of sfGFP. (B) Upper: ESI-MS characterization of CM-sfGFP-NSL-His6 starting material or acyclic sfGFP (left) and cyclic sfGFP (right); Lower: Deconvolution of sfGFP cyclization (CM-sfGFP-NSL-His6: Cal. 28261, Obs. 28263; Cyclic sfGFP: Cal. 27220 , Obs. 27220). The cyclization reaction was performed at $\mathrm{pH} 7.0,37^{\circ} \mathrm{C}$ for 30 min using 25 MM CM-sfGFP-NSL-His6 and $500 \mathrm{nM} \mathrm{Vc1c.}$

Vc1c was able to mediate DARPin9_26 N-terminal labeling. First, a fluorescence peptide RE(EDANS)AN-GI was synthesized as an N-terminal peptide. Then, GLDARPin9_26 having the N-terminal residues "Gly-Leu" was recombinantly expressed (Figure 5A). The reaction was performed at $37^{\circ} \mathrm{C}, \mathrm{pH} 6.5$ with $20 \mathrm{nM} \mathrm{Vclc}$ and $4 \mu \mathrm{M}$ DARPin9_26 and was complete within $30 \mathrm{~min}$. This result showed that Vclc efficiently ligated DARPin9_26 to fluorescent peptides (Figure 5B).

\section{Vc1c-Mediated GFP Cyclization}

Green Fluorescent Protein (GFP) is a widely used reporter for many applications including studies of protein folding, gene translation, and protein-protein interactions (Kalir et al., 2001; Waldo 2003; Magliery et al., 2005). A GFP variant, "super folder" GFP (sfGFP), was developed to reduce aggregation and increase folding efficiency (Pédelacq et al., 2006). In addition, the circular topology of proteins can contribute to improved stability. To demonstrate the feasibility of $\mathrm{Vclc}$ to 


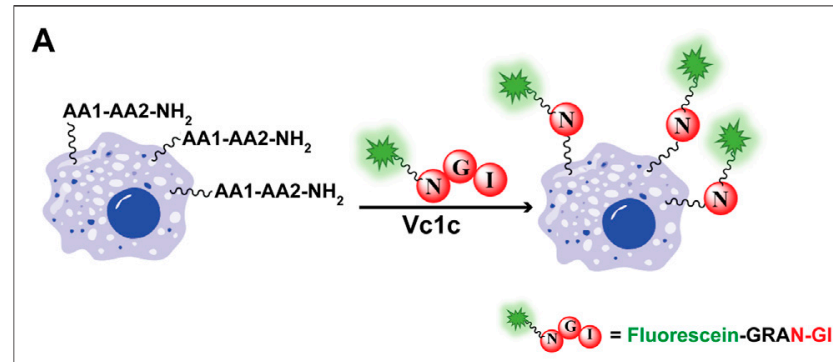

B

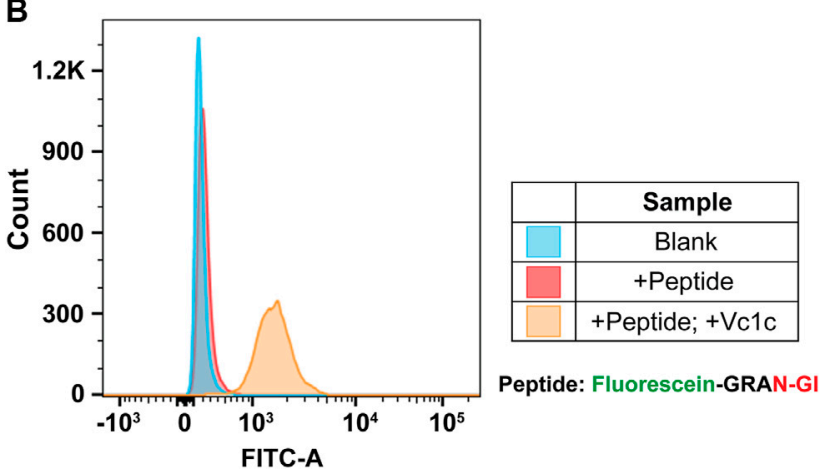

FIGURE 7 | Vc1c-mediated MCF-7 cell labelling. (A) Schematic of MCF7 cell surface amine labelling with the peptide fluorescein-GRANGI using Vc1c. (B) Flow cytometry analysis of MCF-7 labelling with the peptide fluorescein-GRANGI. Untreated cells with neither peptide nor ligase added and cells with only peptide added were used as negative controls. The reaction was conducted at $37^{\circ} \mathrm{C}$ for $1 \mathrm{~h}$ using $50 \mu \mathrm{M}$ fluorescein-peptide and $200 \mathrm{nM}$ Vc1c.

catalyze end-to-end protein cyclization, we expressed sfGFP with an additional N-terminal Met-Ile and a C-terminal AsnSer-Leu-His6 (Figure 6A). The cyclization reaction was performed in the presence of $25 \mu \mathrm{M}$ GFP and $0.5 \mu \mathrm{M} \mathrm{Vclc}$. The reaction was complete within $30 \mathrm{~min}$, as determined by high-resolution ESI-MS (Figure 6B).

\section{Vc1c-Mediated MCF-7 Cell Surface Labeling}

AEP-mediated cell surface labeling is a promising method for cell surface modifications (Bi et al., 2017; Harmand et al., 2021). Previous study has shown that AEP can be used for cell surface modification by specifically labeling the C-terminal hTFR-NHV (Bi et al., 2020). However, the labeling efficiency is limited due to the unsatisfactory amount of receptor protein was expressed on the cell surface. To establish a convenient and highly efficient labeling strategy, we explore the use of PAL enzyme for unspecific cell surface N-terminal amine labeling. To perform the reaction, MCF-7 cells (a typical cancer cell line) were detached and suspended in PBS buffer. The reaction was conducted using $50 \mu \mathrm{M}$ of fluorescein-GRAN-GI and $200 \mathrm{nM}$ of $\mathrm{Vclc}$ at $37^{\circ} \mathrm{C}$ for $1 \mathrm{~h}$. The cells were then washed and suspended in PBS buffer for flow cytometry with FITC channels used to detect fluorescein peptide-labeled cells (Figure 7A). MCF-7 cells were successfully labeled with $\mathrm{Vclc}$ in the presence of fluorescein peptides
(Figure 7B). These findings show that $\mathrm{Vclc}$ is an efficient ligase for the modification of cell surface proteins, and thus this engineered protein could be valuable for biotechnology applications.

\section{CONCLUSION}

In this report, we successfully engineer an AEP from Viola canadensis to an AEP-type ligase or PAL by mutating the residues that reside in the substrate-binding pockets flanking the S1 active site. Ligases are useful for site-specific modification proteins and cell-surface labeling which are valuable tools for biotechnology, drug development, and theranostics. A prerequisite requirement is that they can be used under mild conditions, preferably under physiological conditions. PALs fulfill this requirement. Although PALs and AEPs share similar structure and substrate specificity, PALs are rare compared to AEPs. Thus, the ability to engineer a more commonly found AEP to a PAL will provide an additional ligase with a different ligase profile to expand the repertoire of PALs which can be used alone or combined with another ligase for tandem, orthogonal, and one-pot ligation (Harmand et al., 2018; Wang et al., 2021; Zhang et al., 2021). In addition, we have found that these AEP-type ligases have different tripeptide recognition signal, substrate specificity and optimal $\mathrm{pH}$ for ligation reactions. Importantly, the mutant Vclc can be expressed and purified in yields ranging from 5 to $10 \mathrm{mg} / \mathrm{L}$ of bacteria culture. The engineered ligase $\mathrm{Vclc}$ is one of the most efficient ligases known to date. In addition, we show that the engineered enzyme Vclc is a versatile tool in both peptide and protein cyclization, protein and cell-surface labeling, comparable to the natural or recombinant expressed butelase-1 (Nguyen et al., 2014; Hemu et al. 2021). Together, we provide a method to engineer a ligase and valuable tools for sitespecific modification of proteins which can be further used in theranostic applications.

\section{DATA AVAILABILITY STATEMENT}

The datasets presented in this study can be found in online repositories. The names of the repository/repositories and accession number(s) can be found below: https:/www.rcsb.org/ structure/5ZBI, https://www.rcsb.org/structure/2QYJ, https:// www.rcsb.org/structure/2B3P, https://www.rcsb.org/structure/ 4FGU, https://www.rcsb.org/structure/4NOK, https://www.rcsb. org/structure/4D3Y, https://www.rcsb.org/structure/5H0I, https:// www.rcsb.org/structure/5NIJ, https://www.rcsb.org/structure/ 6DHI, https://www.rcsb.org/structure/6IDV, https://www. rcsb.org/structure/6L4V, https:/www.rcsb.org/structure/6L4W, https://www.rcsb.org/structure/6L4X, https://www.rcsb.org/ structure/4D3X, https://www.rcsb.org/structure/5LUA, https:// www.rcsb.org/structure/6AZT, https://www.rcsb.org/structure/ 5OBT. 


\section{AUTHOR CONTRIBUTIONS}

YC, DZ, XZ, C-FL, and JT designed research; YC, DZ, XZ, and ZW performed research; YC, DZ, and JT analyzed data; and YC, $\mathrm{DZ}$, and JT wrote the paper.

\section{FUNDING}

This research was supported by Academic Research Grant Tier 3 (MOE2016-T3-1-003) from Singapore Ministry of Education (MOE), and Synzyme and Natural Products Center (SYNC, 001304-00001) at Nanyang Technological University.

\section{REFERENCES}

Abe, Y., Shirane, K., Yokosawa, H., Matsushita, H., Mitta, M., Kato, I., et al. (1993). Asparaginyl Endopeptidase of jack Bean Seeds. Purification, Characterization, and High Utility in Protein Sequence Analysis. J. Biol. Chem. 268, 3525-3529. doi:10.1016/s0021-9258(18)53726-1

Abramowitz, N., Schechter, I., and Berger, A. (1967). On the Size of the Active Site in Proteases II. Carboxypeptidase-A. Biochem. Biophysical Res. Commun. 29, 862-867. doi:10.1016/0006-291x(67)90299-9

Alsina, J., Yokum, T. S., Albericio, F., and Barany, G. (2000). A Modified Backbone Amide Linker (BAL) Solid-phase Peptide Synthesis Strategy Accommodating Prolyl, N-Alkylamino Acyl, or Histidyl Derivatives at the C-Terminus. Tetrahedron Lett. 41, 7277-7280. doi:10.1016/s0040-4039(00) 01255-7

Bernath-Levin, K., Nelson, C., Elliott, A. G., Jayasena, A. S., Millar, A. H., Craik, D. J., et al. (2015). Peptide Macrocyclization by a Bifunctional Endoprotease. Chem. Biol. 22, 571-582. doi:10.1016/j.chembiol.2015.04.010

Bi, X., Yin, J., Nguyen, G. K. T., Rao, C., Halim, N. B. A., Hemu, X., et al. (2017). Enzymatic Engineering of Live Bacterial Cell Surfaces Using Butelase 1. Angew. Chem. Int. Ed. 56, 7822-7825. doi:10.1002/anie.201703317

Bi, X., Yin, J., Zhang, D., Zhang, X., Balamkundu, S., Lescar, J., et al. (2020). Tagging Transferrin Receptor with a Disulfide FRET Probe to Gauge the Redox State in Endosomal Compartments. Anal. Chem. 92, 12460-12466. doi:10.1021/ acs.analchem.0c02264

Bork, P. (1993). Hundreds of Ankyrin-like Repeats in Functionally Diverse Proteins: Mobile Modules that Cross Phyla Horizontally. Proteins 17, 363-374. doi:10.1002/prot.340170405

Bottari, A., Capocchi, A., Galleschi, L., Jopova, A., and Saviozzi, F. (1996). Asparaginyl Endopeptidase during Maturation and Germination of Durum Wheat. Physiol. Plant 97, 475-480. doi:10.1111/j.1399-3054.1996.tb00506.x

Cao, Y., Nguyen, G. K. T., Chuah, S., Tam, J. P., and Liu, C.-F. (2016). Butelasemediated Ligation as an Efficient Bioconjugation Method for the Synthesis of Peptide Dendrimers. Bioconjug. Chem. 27, 2592-2596. doi:10.1021/ acs.bioconjchem.6b00538

Cao, Y., Nguyen, G. K. T., Tam, J. P., and Liu, C.-F. (2015). Butelase-mediated Synthesis of Protein Thioesters and its Application for Tandem Chemoenzymatic Ligation. Chem. Commun. 51, 17289-17292. doi:10.1039/ c5cc07227a

Dall, E., and Brandstetter, H. (2016). Structure and Function of Legumain in Health and Disease. Biochimie 122, 126-150. doi:10.1016/j.biochi.2015.09.022

Hara-Nishimura, I., and Hatsugai, N. (2011). The Role of Vacuole in Plant Cell Death. Cell Death Differ 18, 1298-1304. doi:10.1038/cdd.2011.70

Hara-Nishimura, I., Inoue, K., and Nishimura, M. (1991). A Unique Vacuolar Processing Enzyme Responsible for Conversion of Several Proprotein Precursors into the Mature Forms. FEBS Lett. 294, 89-93. doi:10.1016/00145793(91)81349-d

Hara-Nishimura, I., Shimada, T., Hiraiwa, N., and Nishimura, M. (1995). Vacuolar Processing Enzyme Responsible for Maturation of Seed Proteins. J. Plant Physiol. 145, 632-640. doi:10.1016/s0176-1617(11)81275-7

\section{ACKNOWLEDGMENTS}

We would like to thank Assoc Prof Julien Lescar, Hemu Xinya and Wong Yeehwa at the School of Biological Sciences, NTU, Singapore, for their valuable advices and supports. We also thank Professor Lloyd Ruddock (University of Oulu, Finland) for providing the disulfide-promoting plasmids.

\section{SUPPLEMENTARY MATERIAL}

The Supplementary Material for this article can be found online at: https://www.frontiersin.org/articles/10.3389/fchem.2021.768854/ full\#supplementary-material

Harmand, T. J., Bousbaine, D., Chan, A., Zhang, X., Liu, D. R., Tam, J. P., et al. (2018). One-pot Dual Labeling of IgG 1 and Preparation of C-To-C Fusion Proteins through a Combination of Sortase A and Butelase 1. Bioconjug. Chem. 29, 3245-3249. doi:10.1021/acs.bioconjchem.8b00563

Harmand, T. J., Pishesha, N., Rehm, F. B., Ma, W., Pinney, W. B., Xie, Y. J., et al. (2021). Asparaginyl Ligase-Catalyzed One-step Cell Surface Modification of Red Blood Cells. ACS Chem. Biol. 16(7), 1201-1207. doi:10.1021/ acschembio.1c00216

Harris, K. S., Durek, T., Kaas, Q., Poth, A. G., Gilding, E. K., Conlan, B. F., et al. (2015). Efficient Backbone Cyclization of Linear Peptides by a Recombinant Asparaginyl Endopeptidase. Nat. Commun. 6, 1-10. doi:10.1038/ ncomms10199

Harris, K. S., Guarino, R. F., Dissanayake, R. S., Quimbar, P., McCorkelle, O. C., Poon, S., et al. (2019). A Suite of Kinetically superior AEP Ligases Can Cyclise an Intrinsically Disordered Protein. Sci. Rep. 9, 1-13. doi:10.1038/s41598-01947273-7

Hatsugai, N., Yamada, K., Goto-Yamada, S., and Hara-Nishimura, I. (2015). Vacuolar Processing Enzyme in Plant Programmed Cell Death. Front. Plant Sci. 6, 234. doi:10.3389/fpls.2015.00234

Haywood, J., Schmidberger, J. W., James, A. M., Nonis, S. G., Sukhoverkov, K. V., Elias, M., et al. (2018). Structural Basis of Ribosomal Peptide Macrocyclization in Plants. Elife 7, e32955. doi:10.7554/eLife.32955

Hemu, X., El Sahili, A., Hu, S., Wong, K., Chen, Y., Wong, Y. H., et al. (2019). Structural Determinants for Peptide-Bond Formation by Asparaginyl Ligases. Proc. Natl. Acad. Sci. U S A. 116, 11737-11746. doi:10.1073/pnas.1818568116

Hemu, X., El Sahili, A., Hu, S., Zhang, X., Serra, A., Goh, B. C., et al. (2020). Turning an Asparaginyl Endopeptidase into a Peptide Ligase. ACS Catal. 10, 8825-8834. doi:10.1021/acscatal.0c02078

Hemu, X., Qiu, Y., Nguyen, G. K. T., and Tam, J. P. (2016). Total Synthesis of Circular Bacteriocins by Butelase 1. J. Am. Chem. Soc. 138, 6968-6971. doi: $10.1021 /$ jacs.6b04310

Hemu, X., Zhang, X., Nguyen, G. K., To, J., Serra, A., Loo, S., et al. (2021). Characterization and application of natural and recombinant butelase- 1 to improve industrial enzymes by end-to-end circularization. RSC Advances 11, 23105-23112.

Ishii, S.-i., Abe, Y., Matsushita, H., and Kato, I. (1990). An Asparaginyl Endopeptidase Purified from Jackbean Seeds. J. Protein Chem. 9, 294-295.

Jackson, M. A., Gilding, E. K., Shafee, T., Harris, K. S., Kaas, Q., Poon, S., et al. (2018). Molecular Basis for the Production of Cyclic Peptides by Plant Asparaginyl Endopeptidases. Nat. Commun. 9, 2411-2412. doi:10.1038/ s41467-018-04669-9

Jackson, M. A., Nguyen, L. T., Gilding, E. K., Durek, T., and Craik, D. J. (2020). Make it or Break it: Plant AEPs on Stage in Biotechnology. Biotechnol. Adv. 45, 107651. doi:10.1016/j.biotechadv.2020.107651

Kalir, S., McClure, J., Pabbaraju, K., Southward, C., Ronen, M., Leibler, S., et al. (2001). Ordering Genes in a Flagella Pathway by Analysis of Expression Kinetics from Living Bacteria. Science 292, 2080-2083. doi:10.1126/ science. 1058758

Loo, S., Kam, A., Xiao, T., Nguyen, G. K., Liu, C. F., and Tam, J. P. (2016). Identification and Characterization of Roseltide, a Knottin-type Neutrophil 
Elastase Inhibitor Derived from Hibiscus sabdariffa. Sci. Rep. 6, 39401-39416. doi:10.1038/srep39401

Magliery, T. J., Wilson, C. G. M., Pan, W., Mishler, D., Ghosh, I., Hamilton, A. D., et al. (2005). Detecting Protein-Protein Interactions with a Green Fluorescent Protein Fragment Reassembly Trap: Scope and Mechanism. J. Am. Chem. Soc. 127, 146-157. doi:10.1021/ja046699g

Min, W., and Jones, D. H. (1994). In Vitro splicing of Concanavalin A Is Catalyzed by Asparaginyl Endopeptidase. Nat. Struct. Mol. Biol. 1, 502-504. doi:10.1038/ nsb0894-502

Müntz, K., and Shutov, A. D. (2002). Legumains and Their Functions in Plants. Trends Plant Science 7, 340-344. doi:10.1016/s1360-1385(02)02298-7

Nguyen, G. K. T., Cao, Y., Wang, W., Liu, C. F., and Tam, J. P. (2015a). Site-Specific N-Terminal Labeling of Peptides and Proteins Using Butelase 1 and Thiodepsipeptide. Angew. Chem. 127, 15920-15924. doi:10.1002/ ange. 201506810

Nguyen, G. K. T., Hemu, X., Quek, J.-P., and Tam, J. P. (2016). Butelase-Mediated Macrocyclization Ofd-Amino-Acid-Containing Peptides. Angew. Chem. Int. Ed. 55, 12802-12806. doi:10.1002/anie.201607188

Nguyen, G. K. T., Kam, A., Loo, S., Jansson, A. E., Pan, L. X., and Tam, J. P. (2015b). Butelase 1: a Versatile Ligase for Peptide and Protein Macrocyclization. J. Am. Chem. Soc. 137, 15398-15401. doi:10.1021/jacs.5b11014

Nguyen, G. K. T., Wang, S., Qiu, Y., Hemu, X., Lian, Y., and Tam, J. P. (2014). Butelase 1 Is an Asx-specific Ligase Enabling Peptide Macrocyclization and Synthesis. Nat. Chem. Biol. 10, 732-738. doi:10.1038/nchembio. 1586

Nonis, S. G., Haywood, J., Schmidberger, J. W., Mackie, E. R. R., Soares da Costa, T. P., Bond, C. S., et al. (2021). Structural and Biochemical Analyses of Concanavalin A Circular Permutation by jack Bean Asparaginyl Endopeptidase. The Plant Cell 33, 2794-2811. doi:10.1093/plcell/koab130

Pédelacq, J.-D., Cabantous, S., Tran, T., Terwilliger, T. C., and Waldo, G. S. (2006). Engineering and Characterization of a Superfolder green Fluorescent Protein. Nat. Biotechnol. 24, 79-88. doi:10.1038/nbt1172

Ross, J. S. (2009). Breast Cancer Biomarkers and HER2 Testing after 10 Years of Anti-HER2 Therapy. Drug News Perspect. 22, 93-106. doi:10.1358/ dnp.2009.22.2.1334452

Saska, I., Gillon, A. D., Hatsugai, N., Dietzgen, R. G., Hara-Nishimura, I., Anderson, M. A., et al. (2007). An Asparaginyl Endopeptidase Mediates In Vivo Protein Backbone Cyclization. J. Biol. Chem. 282, 29721-29728. doi:10.1074/jbc.m705185200

Sheldon, P. S., Keen, J. N., and Bowles, D. J. (1996). Post-translational Peptide Bond Formation during Concanavalin A Processing In Vitro. Biochem. J. 320, 865-870. doi:10.1042/bj3200865

Shimada, T., Yamada, K., Kataoka, M., Nakaune, S., Koumoto, Y., Kuroyanagi, M., et al. (2003). Vacuolar Processing Enzymes Are Essential for Proper Processing of Seed Storage Proteins in Arabidopsis thaliana. J. Biol. Chem. 278, 32292-32299. doi:10.1074/jbc.m305740200

Stumpp, M. T., Binz, H. K., and Amstutz, P. (2008). DARPins: a New Generation of Protein Therapeutics. Drug Discov. Today 13, 695-701. doi:10.1016/ j.drudis.2008.04.013

Tam, J. P., Chan, N.-Y., Liew, H. T., Tan, S. J., and Chen, Y. (2020). Peptide Asparaginyl Ligases-Renegade Peptide Bond Makers. Sci. China Chem. 63 (3), 1-12. doi:10.1007/s11426-019-9648-3

Waldo, G. S. (2003). Improving Protein Folding Efficiency by Directed Evolution Using the GFP Folding Reporter. Directed Enzyme Evol. 230, 343-359. doi:10.1385/1-59259-396-8:343

Wang, Z., Zhang, D., Hemu, X., Hu, S., To, J., Zhang, X., et al. (2021). Engineering Protein Theranostics Using Bio-Orthogonal Asparaginyl Peptide Ligases. Theranostics 11, 5863-5875. doi:10.7150/thno.53615

Yamada, K., Basak, A. K., Goto-Yamada, S., Tarnawska-Glatt, K., and HaraNishimura, I. (2020). Vacuolar Processing Enzymes in the Plant Life Cycle. New Phytol. 226, 21-31. doi:10.1111/nph.16306

Yang, R., Wong, Y. H., Nguyen, G. K. T., Tam, J. P., Lescar, J., and Wu, B. (2017). Engineering a Catalytically Efficient Recombinant Protein Ligase. J. Am. Chem. Soc. 139, 5351-5358. doi:10.1021/jacs.6b12637

Zauner, F. B., Elsässer, B., Dall, E., Cabrele, C., and Brandstetter, H. (2018). Structural Analyses of Arabidopsis thaliana Legumain $\gamma$ Reveal Differential Recognition and Processing of Proteolysis and Ligation Substrates. J. Biol. Chem. 293, 8934-8946. doi:10.1074/jbc.m117.817031

Zhang, D., Wang, Z., Hu, S., Balamkundu, S., To, J., Zhang, X., et al. (2021). pHControlled Protein Orthogonal Ligation Using Asparaginyl Peptide Ligases. J. Am. Chem. Soc. 143(23), 8704-8712. doi:10.1021/jacs.1c02638

Conflict of Interest: The authors declare that the research was conducted in the absence of any commercial or financial relationships that could be construed as a potential conflict of interest.

Publisher's Note: All claims expressed in this article are solely those of the authors and do not necessarily represent those of their affiliated organizations, or those of the publisher, the editors and the reviewers. Any product that may be evaluated in this article, or claim that may be made by its manufacturer, is not guaranteed or endorsed by the publisher.

Copyright () 2021 Chen, Zhang, Zhang, Wang, Liu and Tam. This is an open-access article distributed under the terms of the Creative Commons Attribution License (CC $B Y$ ). The use, distribution or reproduction in other forums is permitted, provided the original author(s) and the copyright owner(s) are credited and that the original publication in this journal is cited, in accordance with accepted academic practice. No use, distribution or reproduction is permitted which does not comply with these terms. 